\title{
Void Reactivity Coefficient Analysis during Void Fraction Changes in Innovative BWR Assemblies
}

\author{
Andrius Slavickas, Raimondas Pabarčius, Aurimas Tonkūnas, \\ Gediminas Stankūnas, and Eugenijus Ušpuras
}

Lithuanian Energy Institute, Breslaujos Straße 3, 44403 Kaunas, Lithuania

Correspondence should be addressed to Andrius Slavickas; andrius.slavickas@lei.lt

Received 23 October 2014; Revised 1 April 2015; Accepted 8 April 2015

Academic Editor: Rafael Miró

Copyright (c) 2015 Andrius Slavickas et al. This is an open access article distributed under the Creative Commons Attribution License, which permits unrestricted use, distribution, and reproduction in any medium, provided the original work is properly cited.

\begin{abstract}
The study of the void reactivity variation in innovative BWR fuel assemblies is presented in this paper. The innovative assemblies are loaded with high enrichment fresh $\mathrm{UO}_{2}$ and $\mathrm{MOX}$ fuels. $\mathrm{UO}_{2}$ fuel enrichment is increased above existing design limitations for LWR fuels $(>5 \%)$. MOX fuel enrichment with fissile $\mathrm{Pu}$ content is established to achieve the same burnup level as that of high enrichment $\mathrm{UO}_{2}$ fuel. For the numerical analysis, the TRITON functional module of SCALE 6.1 code with the 238-group ENDF/BVI cross section data library was applied. The investigation of the void reactivity feedback is performed in the entire $0-100 \%$ void fraction range. Higher values of void reactivity coefficient for assembly loaded with MOX fuel are found in comparison with values for assembly loaded with $\mathrm{UO}_{2}$ fuel. Moreover, coefficient values for MOX fuel are positive over $75 \%$ void fraction. The variation of the void reactivity coefficient is explained by the results of the decomposition analysis based on four-factor formula and neutron absorption reactions for main isotopes. Additionally, the impact of the moderation enhancement on the void reactivity coefficient was investigated for the innovative assembly with MOX fuel.
\end{abstract}

\section{Introduction}

The analysis presented in this paper is a continuation of the work on study of void reactivity coefficient [1] in innovative BWR fuel assemblies, where the behavior of void reactivity coefficient over fuel burn-up was studied. Values of void reactivity coefficient were calculated for two states representing the void fraction increase from $40 \%$ to $100 \%$. These void fractions correspond to the typical BWR core states: normal operation (40\%) and core conditions during the loss of coolant accident (100\%). Values of void reactivity coefficient calculated for this void fraction increase only the estimate of the final effect of changed moderation conditions. However, the reactivity response to changed moderation conditions is not uniform in the entire void fraction range. The continuous operational control of BWR core is typically accomplished by the adjustment of the coolant flow rate through the core, which affects the void fraction changes. Thus, for the estimation of core controllability by the coolant flow rate, the void reactivity change at local void fractions should be known.

Void reactivity coefficient for BWR fuel has been studied for typical void fraction values of $0 \%, 40 \%$, and $70 \%$ [2-4]. $0 \%$ and $70 \%$ void fractions were chosen in these studies, since they correspond to moderation conditions at the bottom and the top of the BWR fuel assembly during normal operation, respectively. Thereby, the investigation of the void reactivity variation in the entire $0-100 \%$ void fraction range was initiated at the Lithuanian Energy Institute. This paper presents results on analysis of void reactivity feedback at all possible moderation conditions appearing during normal operation and accident transients.

Void reactivity variations during void fraction changes depend on the isotopic fuel composition, as well. The relationship between the void reactivity feedback and the fuel isotopic composition was studied in the past [5]. Only the qualitative analysis was performed in that study. It was estimated which isotopes contribute to the positive or negative 

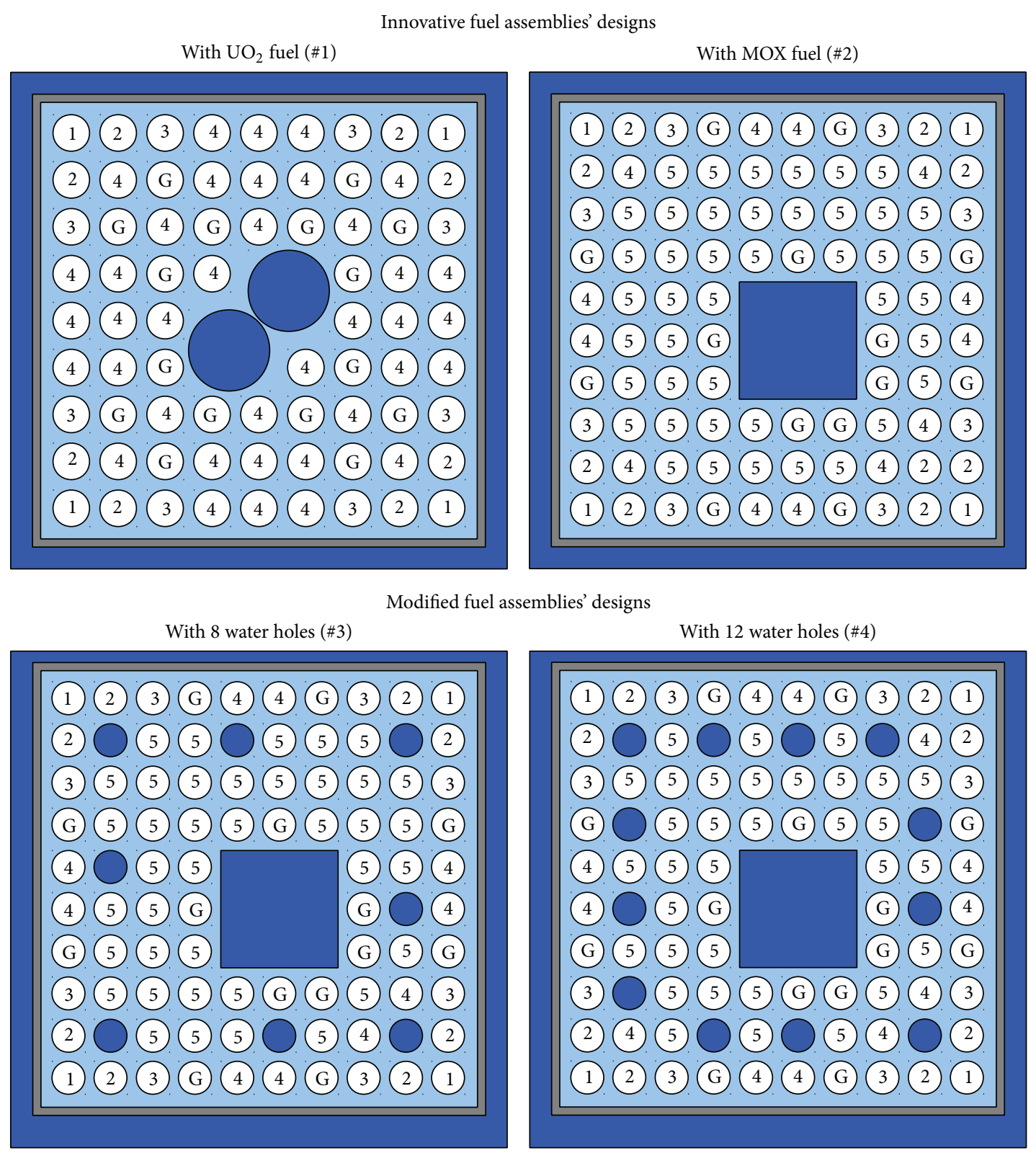

FIGURE 1: Innovative and modified designs of assemblies.

void reactivity feedback. Meanwhile, in the current study, the quantitative decomposition analysis was fulfilled. In addition, values of void reactivity coefficient were decomposed to separate values based on four-factor formula. Decomposed values of void reactivity coefficient provide useful insights for describing the behavior of the void reactivity feedback in detail. In this study, it is shown that the decomposition analysis is applicable to the analysis of void reactivity variations during void fraction changes as well as during the fuel irradiation.

\section{Methodology}

2.1. Designs of Fuel Assemblies. Innovative designs of BWR fuel assemblies used for the analysis of void reactivity coefficient are based on the benchmark problem suite for reactor physics study of LWR next generation fuels [6]. This benchmark problem was suggested by the party working on Reactor Physics for LWR next generation fuels, which was organized in Japan Atomic Energy Research Institute (JAERI). It should be noted that the enrichment of next generation fuel was increased above existing design limitations for LWR fuels. The discharge burn-up target value of the next generation LWR fuels is set to reach $70 \mathrm{GWd} / \mathrm{t}$. The $\mathrm{UO}_{2}$ and MOX fuels were included in the benchmark specifications.

The lattice configurations of innovative BWR fuel assemblies used for this study are presented in Figure 1. Design of assemblies with $\mathrm{UO}_{2}$ fuel consists of $9 \times 9$ lattice configuration with 2 large water channels and 74 fuel rods of varying ${ }^{235} \mathrm{U}$ enrichment. Initial enrichment varies from 
$3 \mathrm{wt} \%$ to $6.3 \mathrm{wt} \%$ for fuel mixtures (marked by numbers 14). 16 fuel rods contain $\mathrm{UO}_{2}-\mathrm{Gd}_{2} \mathrm{O}_{3}$ mixture (marked as $\mathrm{G}$ ). Meanwhile, design of assemblies with MOX fuel consists of $10 \times 10$ lattice configuration with one large water channel in the centre and 91 fuel rods with five different $(\mathrm{U}-\mathrm{Pu}) \mathrm{O}_{2}$ mixtures and one $\mathrm{UO}_{2}-\mathrm{Gd}_{2} \mathrm{O}_{3}$ mixture. Fissile $\mathrm{Pu}$ isotope content is established to achieve the same burn-up level as high enrichment $\mathrm{UO}_{2}$ fuel, and it varies from $2.6 \mathrm{wt} \%$ to $10.2 \mathrm{wt} \%$ for fuel mixtures.

The use of MOX fuel in reactor core causes a harder neutron spectrum and, consequently, influences a void reactivity coefficient and other neutronic characteristics $[8,9]$. Thus, MOX-fueled reactors consist of cores partly loaded with MOX fuel and the rest of the core loaded with $\mathrm{UO}_{2}$ fuel to meet safety margins. However, since the fuel contains a large fraction of ${ }^{238} \mathrm{U}$, it also breeds plutonium and other minor actinides, which decrease the efficiency of plutonium depletion. The plutonium utilization could be more effective if the full core was loaded with MOX fuel. Previous works [1012] were performed in order to evaluate this feasibility. These studies showed that it is possible to have a full MOX core by introducing the enhanced moderation in fuel assemblies.

The enhanced moderation was achieved by replacing a small fraction of fuel per assembly with water holes. Two designs of fuel assemblies with extra moderation were analyzed. Modified designs of fuel assemblies with 8 and 12 water holes in place of fuel are presented in Figure 1. Moderator-to-fuel ratio increases from 1.90 to 2.18 and 2.35 for assemblies with 8 and 12 water holes, respectively. More details on designs of fuel assemblies can be found in previous work [1].

2.2. Software. The neutron transport calculations for BWR fuel assemblies were performed with the TRITON functional module utilizing the ENDF/B-VI based 238-neutron-energygroup library distributed with SCALE 6.1 code [13]. TRITON module can be used to provide problem dependent crosssection processing followed by multigroup transport calculations for one-, two-, and three-dimensional configurations. The TRITON T-DEPL sequence was used for void reactivity coefficient investigation.

The validation of SCALE code and TRITON module performed by SCALE developers includes a suite of code-to-code comparisons initiated by JAERI for LWR next generation fuels, which are studied in this paper. Void reactivity calculations performed as a part of this code-to-code comparison for innovative BWR assembly with $\mathrm{UO}_{2}$ fuel are illustrated in Figure 2 [7]. TRITON shows an excellent agreement with the results of other codes.

A validation of TRITON combined with the methodology used in this study was performed for modern BWR assembly loaded with MOX fuel. This modern fuel assembly corresponds to the ATRIUM-10 assembly manufactured by Areva Company. The obtained neutron results were compared with the ones presented in the NEA BWR-MOX benchmark for the same assembly design $[14,15]$. The comparison of TRITON results with benchmark participants' results for $k_{\text {eff }}$ calculations is depicted in Figure 3. It can be seen that

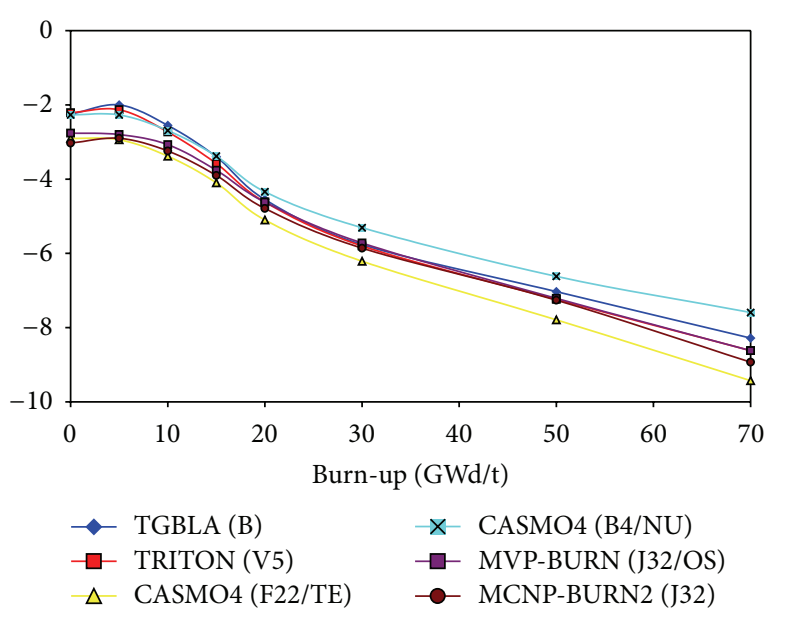

FIGURE 2: Void reactivity effect ( $0 \%-70 \%)$ over burn-up for innovative assembly with $\mathrm{UO}_{2}$ fuel [7].

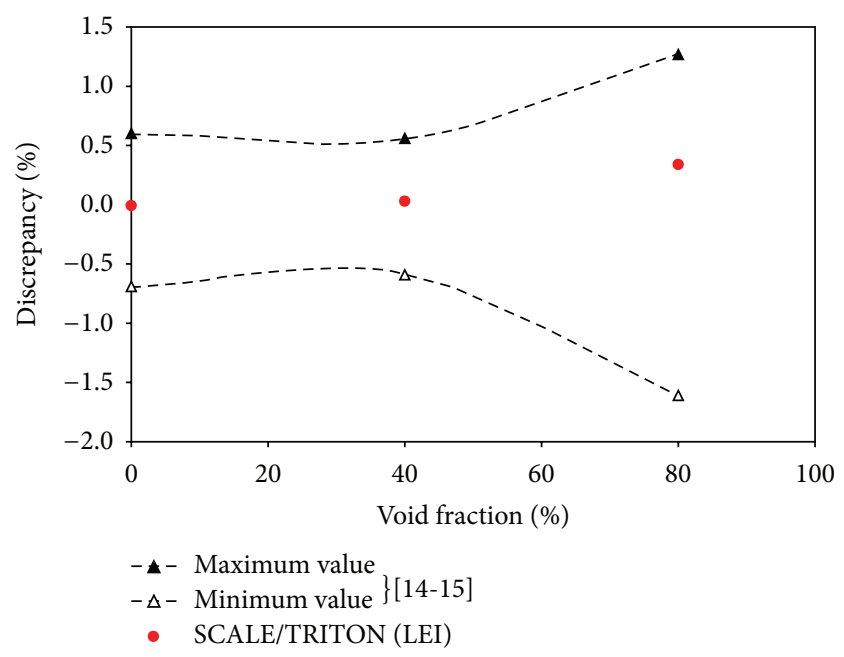

FIgure 3: Comparison of the SCALE code and NEA BWR-MOX benchmark results.

TRITON shows an excellent agreement with benchmark participants' results. The increase of discrepancies is observed at higher void fractions.

2.3. Void Reactivity Feedback Calculation. BWR assemblies are very heterogeneous since the two-phase flow occurs in the reactor core during the operation. There are bypass regions in BWR assemblies, which are separated from the two-phase flow: central water channels, water holes, and gaps between neighboring assemblies. A single-phase flow ( $0 \%$ void fraction) was assumed for the bypass regions with density $0.737 \mathrm{~g} / \mathrm{cm}^{3}$. Meanwhile, in the regions with twophase homogeneous void, a fraction ranging from $0 \%$ to $100 \%$ $\left(0.037 \mathrm{~g} / \mathrm{cm}^{3}\right)$ was assumed.

The void reactivity coefficient, varying in the entire $0-100 \%$ void fraction range, was estimated by calculating reactivity changes by void fraction increases in $5 \%$ steps. The 


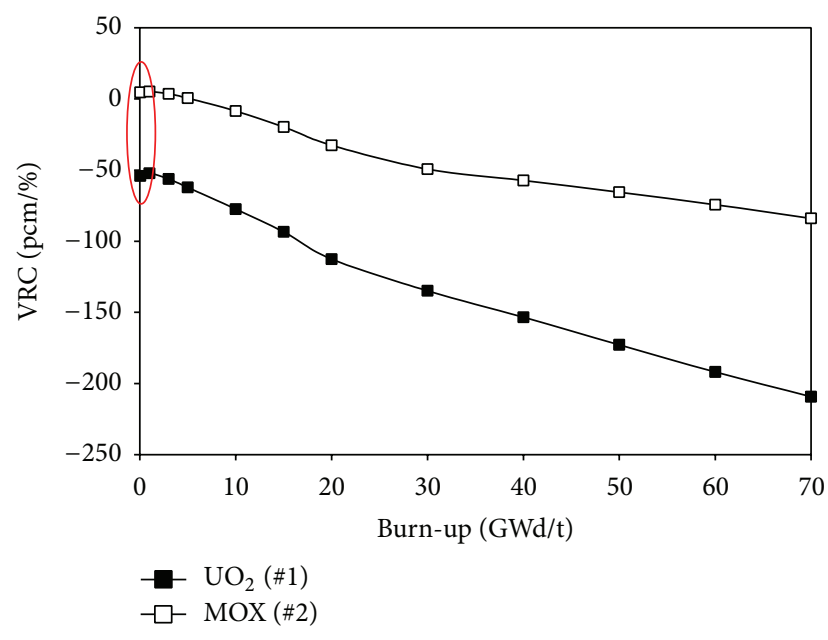

(a)

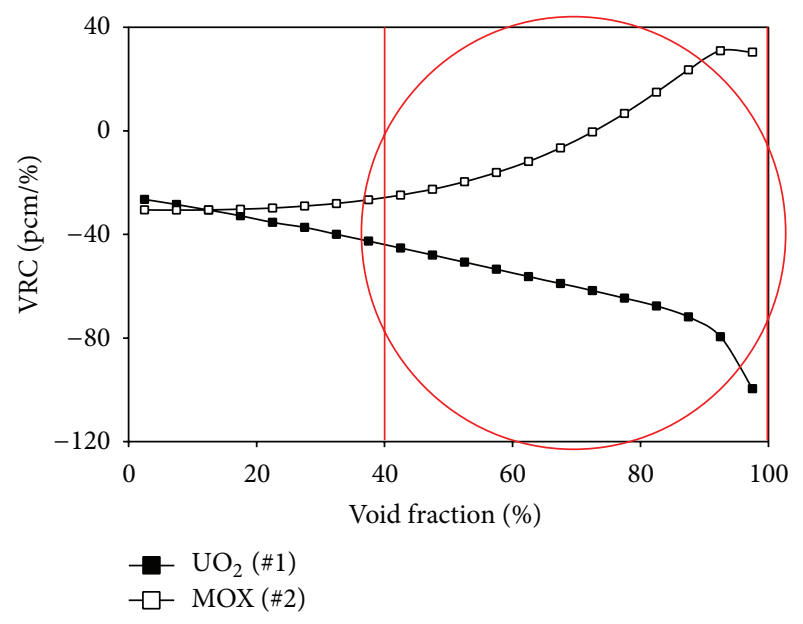

(b)

FIGURE 4: VRC over burn-up and void fraction for innovative fuel assemblies.

void reactivity coefficient is defined as a ratio of the reactivity change to void fraction change:

$$
\alpha(v)=\frac{\Delta \rho_{\text {inf }}}{\Delta v} .
$$

The decomposition analysis was performed to explain the void reactivity feedback. For this purpose, the total void reactivity coefficient value was decomposed into separate components, which represent a contribution of the individual isotope to the void reactivity feedback. The TRITON module can output fractional absorptions data for individual isotopes $\left(a_{i}\right)$. Accordingly, the void coefficient can be expressed as follows:

$$
\alpha(v)=\frac{\Delta \sum\left(-a_{i} / k_{\mathrm{inf}}\right)}{\Delta v} .
$$

In addition, the decomposition analysis based on four-factor formula was performed. The void coefficient for separate factors can be expressed as follows:

$$
\begin{aligned}
\alpha(v)= & \alpha(v, \eta)+\alpha(v, f)+\alpha(v, p)+\alpha(v, \varepsilon) \\
= & \frac{\Delta \eta}{k_{\mathrm{inf}} \cdot \eta \cdot \Delta v}+\frac{\Delta f}{k_{\mathrm{inf}} \cdot f \cdot \Delta v}+\frac{\Delta p}{k_{\mathrm{inf}} \cdot p \cdot \Delta v} \\
& +\frac{\Delta \varepsilon}{k_{\mathrm{inf}} \cdot \varepsilon \cdot \Delta v} .
\end{aligned}
$$

Here $\eta$ is the reproduction number, $f$ is the thermal utilization factor, $p$ is the resonance escape probability, and $\varepsilon$ is the fast fission factor.

\section{Results}

3.1. Void Reactivity Coefficient for Innovative Designs of Fuel Assemblies. The behavior of void reactivity coefficient (VRC) over the fuel burn-up is shown in Figure 4 for void fraction increase from $40 \%$ to $100 \%$ (results of [1]). It can be seen that void reactivity coefficient has strong dependence on the fuel burn-up. The least negative values for designs of assemblies with $\mathrm{UO}_{2}$ and MOX fuel are for the fresh fuel. With this in the mind, the fresh fuel has been considered for the present analysis of the void reactivity coefficient in the entire $0-100 \%$ void fraction range. The variation of void reactivity coefficient over the void fraction is also demonstrated in Figure 4. It can be seen that the void reactivity coefficient for both fuel types is negative at $0-75 \%$ void fraction range. However, coefficient values for MOX fuel are increasing with voiding until becoming positive at over $75 \%$ void fraction. Thus, positive void coefficient for fresh MOX fuel in the case of void fraction increase from $40 \%$ to $100 \%$ is determined by positive values in the $75-100 \%$ void fraction range (corresponding values are marked by red cycle in Figure 4(b)). It means that a positive void reactivity feedback for studied cases occurs only over normal operation conditions for design of assemblies with fresh MOX fuel. Positive values of the void reactivity coefficient in this void fraction range may lead to decreased controllability of the reactor core during some transients like the loss of coolant accident.

The decomposition of four-factor formula is presented in Figure 5. It can be seen that the resonance escape probability $(p)$ and the fast fission factor $(\varepsilon)$ vary the most during void fraction increase: values for the resonance escape probability decrease, while values for the fast fission factor increase. Positive values of void reactivity coefficient indicate an increase of factor during void fraction increase, while negative values indicate a decrease. The total value of void reactivity coefficient is mostly determined by the sum of these two factors. The total values of void reactivity coefficient are negative until the decrease of values of resonance escape probability is larger than the increase of values of fast fission factor. However, the values of fast fission factor increase more than the values of resonance escape probability decrease in case of MOX fuel at high void fraction. It results in the total positive values for MOX fuel in the $75-100 \%$ void fraction range. 


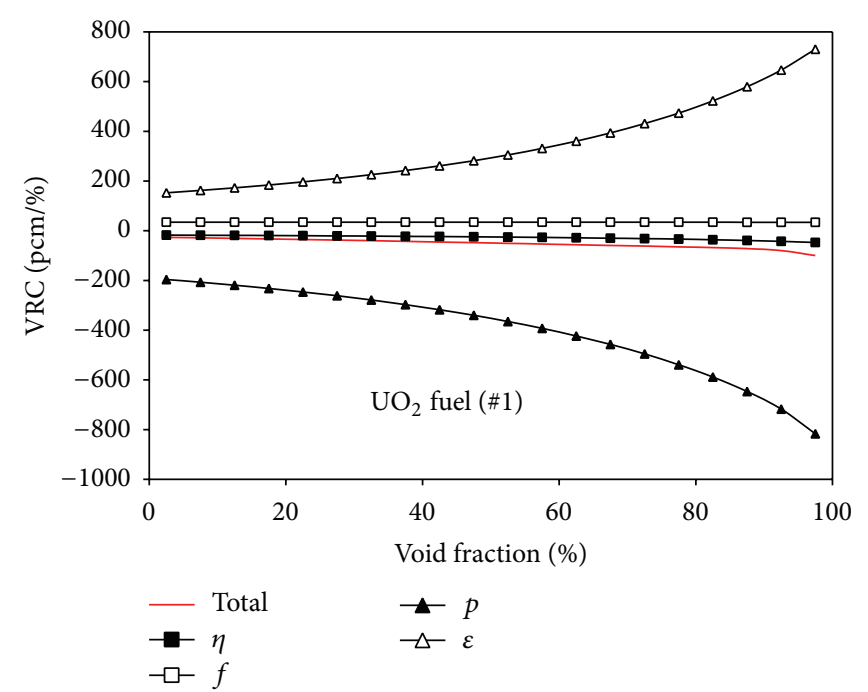

(a)

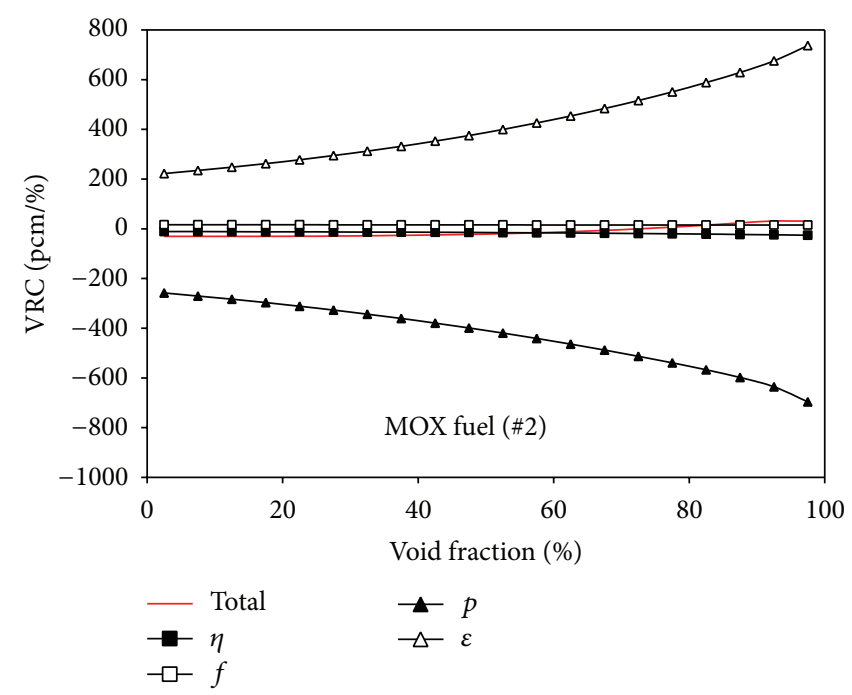

(b)

FIGURE 5: Decomposition of four factors formula in case of $\mathrm{UO}_{2}$ and MOX fuels.

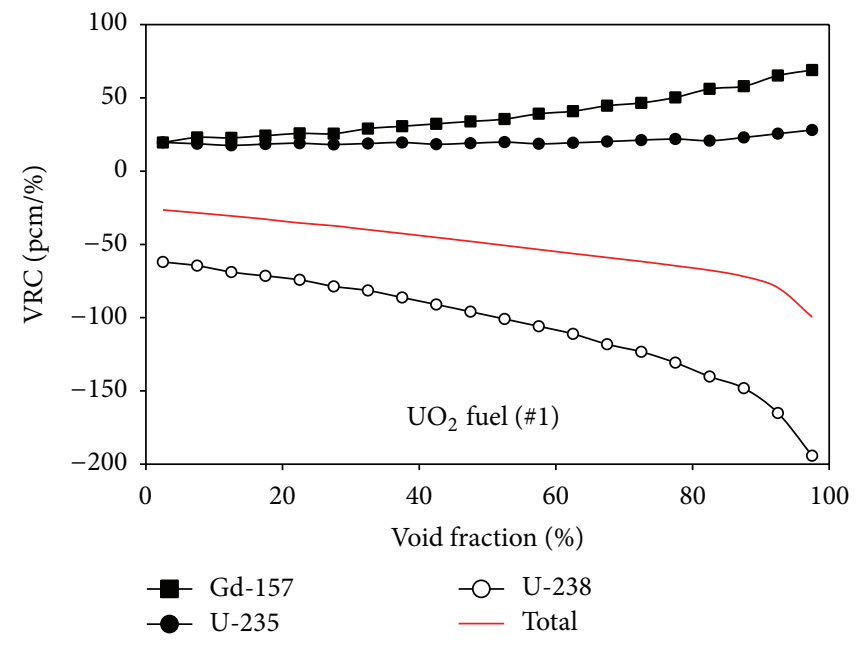

(a)

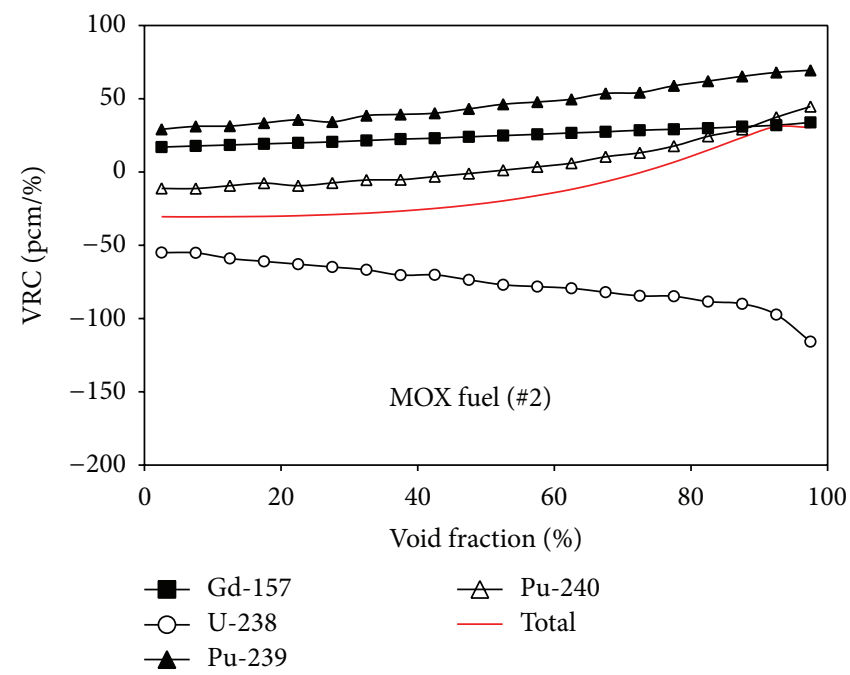

(b)

FIGURE 6: Decomposition of VRC values for separate isotopes in case of $\mathrm{UO}_{2}$ and MOX fuels.

The results of isotopic decomposition analysis for innovative assemblies with fresh $\mathrm{UO}_{2}$ and MOX fuels are shown in Figure 6. Only those isotopes are presented, which have the substantial impact on the void reactivity coefficient. Meanwhile the impact of other isotopes $\left({ }^{155} \mathrm{Gd}\right.$ and ${ }^{238} \mathrm{Pu},{ }^{241} \mathrm{Pu}$, and ${ }^{242} \mathrm{Pu}$ ) on the void reactivity feedback is significantly smaller (less than $10 \mathrm{pcm} / \%$ ).

As can be seen from Figure $5,{ }^{238} \mathrm{U}$ isotope has the strongest impact on the values of coefficients of negative void reactivity for both fuel types in the entire void fraction range. Negative values mean that the neutron absorption of ${ }^{238} \mathrm{U}$ isotope increases during the void fraction increase. This increase is related with neutron spectrum changes during void fraction increase (Figure 7). The fast and resonance neutron flux increases, while the thermal neutron flux decreases during voiding. Thus, the total ${ }^{238} \mathrm{U}$ absorption increases during voiding, since the absorption for this isotope mostly occurs in the resonance neutron region.

Accordingly, coefficient values of ${ }^{157} \mathrm{Gd}$ and fissile isotopes $\left({ }^{235} \mathrm{U}\right.$ and $\left.{ }^{239} \mathrm{Pu}\right)$ are positive, since the absorption of neutrons decreases during the void fraction increase. The neutron absorption in these nuclides occurs mostly in the thermal neutron region. During the voiding, the neutron absorption in this region decreases, since the thermal neutron flux decreases. The decrease of thermal neutron flux is related not only to reduced moderation conditions, but also to the decrease of the resonance escape probability.

Meanwhile, coefficient values for ${ }^{240} \mathrm{Pu}$ vary from negative (in the $0-50 \%$ void fraction range) to positive (in the $50-100 \%$ range). The decomposition of values of void 


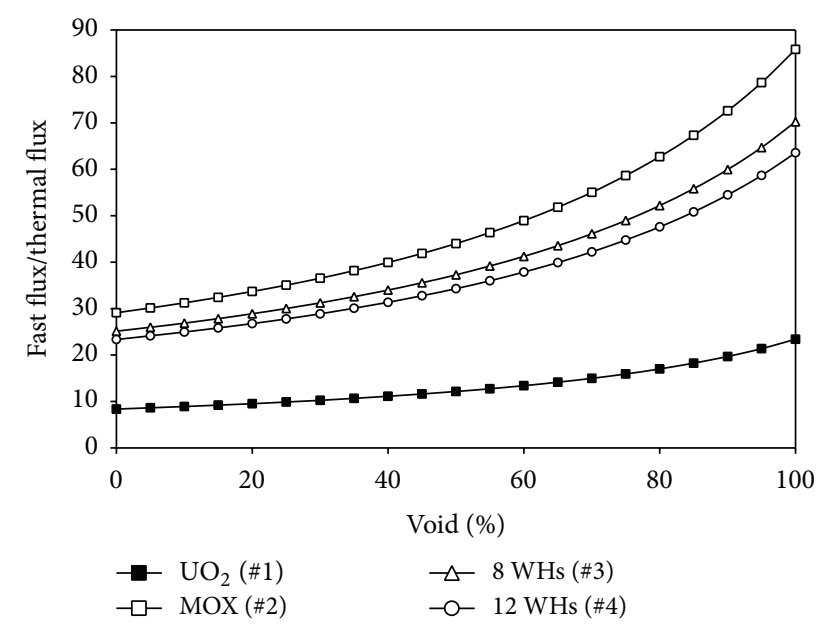

FIgURE 7: Neutron spectrum for innovative designs of assemblies.

reactivity coefficient for ${ }^{240} \mathrm{Pu}$ capture and fission reactions is shown in Figure 8. It can be seen that the increase of values for ${ }^{240} \mathrm{Pu}$ during void fraction increase matches the increase of values for neutrons capture reaction. Most of the neutron absorption on ${ }^{240} \mathrm{Pu}$ takes place in the thermal peaks at $1 \mathrm{eV}$, following the region below $1 \mathrm{eV}$ and then in the resonance neutron region, in this order of importance. The neutron capture in the first two regions decreases, while the capture in the resonance region increases during voiding. Values of the void reactivity coefficient for ${ }^{240} \mathrm{Pu}$ are positive, since the increase of neutrons in the resonance region is not sufficient to compensate for the decrease of thermal neutron absorption, and this provides a positive contribution to the void reactivity feedback. The small negative contribution to the void reactivity feedback of ${ }^{240} \mathrm{Pu}$ in the $0-50 \%$ void fraction range is related to a relatively small decrease of the neutron capture in comparison with the decrease of total reactivity in that void fraction range. The decrease of the neutron capture is greater than total reactivity of MOX fuel assembly above $50 \%$ void fraction. It results in the positive contribution to the void reactivity feedback.

3.2. Void Reactivity Feedback for Modified Fuel Designs of Assemblies. There are concerns associated with the use of MOX fuel in the comparison with the uranium fuel. Many plutonium isotopes have larger absorption cross-sections than uranium ones, so thermal absorption of the fuel with plutonium is larger compared to uranium, which leads to a harder neutron spectrum. As it was shown in Section 3.1, the positive void reactivity coefficient is observed for fresh MOX fuel for void fraction over $75 \%$. The positive void reactivity feedback of the fresh MOX fuel assembly (\#2) could be explained by the harder neutron spectrum. The implementation of additional water holes (WHs) in place of selected fuel enhanced neutron moderation and the neutron spectrum became softer (Figure 7).

The comparison of the void reactivity coefficient in innovative fuel assembly design loaded with MOX fuel (results of the previous section) and in modified designs of assemblies

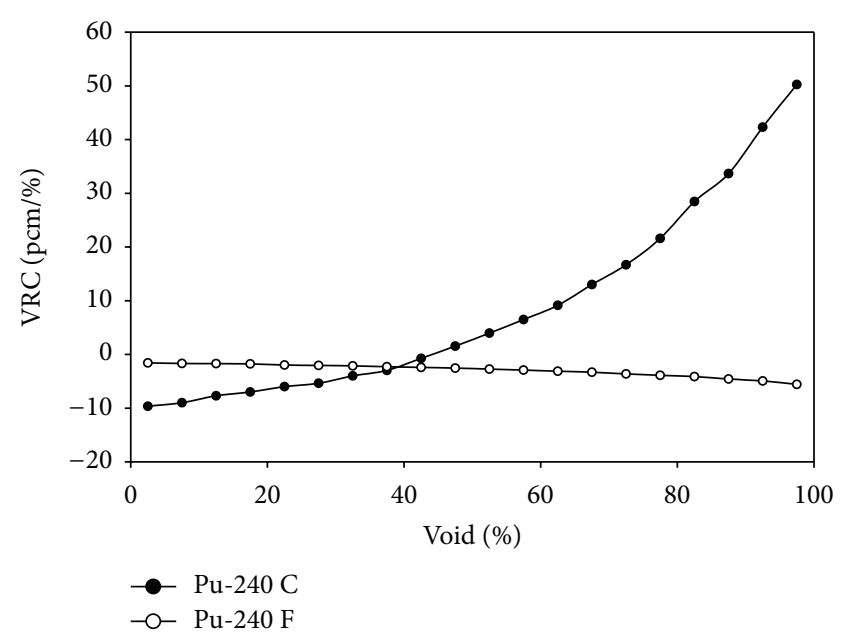

FIGURE 8: Decomposition of VRC values for ${ }^{240} \mathrm{Pu}$ neutrons capture $(\mathrm{C})$ and fission $(\mathrm{F})$ reactions.

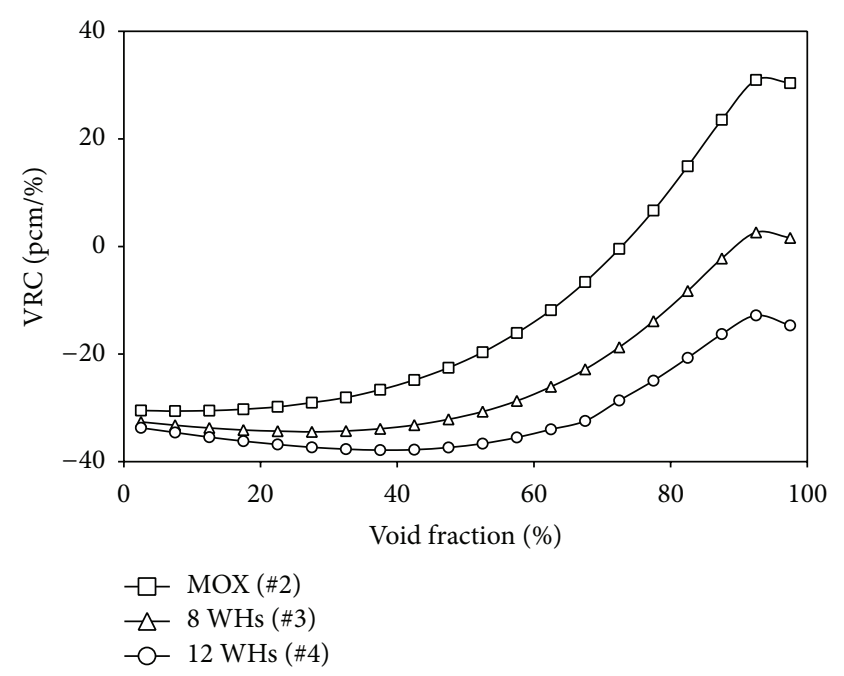

FIGURE 9: Void reactivity coefficient over void fraction for modified MOX fuel assemblies.

with water holes is depicted in Figure 9. The important result is that the void coefficient is lower for enhanced neutron moderation cases in the entire void fraction range. Positive values for the design of assemblies with 8 water holes (assembly \#3, see Figure 1) are observed at $90-100 \%$ void fraction range. Meanwhile, for the assembly design with 12 water holes (assembly \#4, see Figure 1) coefficient values are negative in the entire void fraction range.

The enhanced moderation softened neutron spectrum. The fast fission factor was reduced by $74 \mathrm{pcm} / \%$ at $100 \%$ void fraction. In comparison, the thermal fission factor increased by only $30 \mathrm{pcm} / \%$ (Figure 10). That results in negative void reactivity coefficient for the assembly design with 12 water holes in the entire void fraction range. The impact of the main isotopes on the behavior of the void coefficient of extra moderated assemblies is presented in Figure 11. It is seen that the positive impact of ${ }^{239} \mathrm{Pu}$ and ${ }^{240} \mathrm{Pu}$ on the void coefficient 


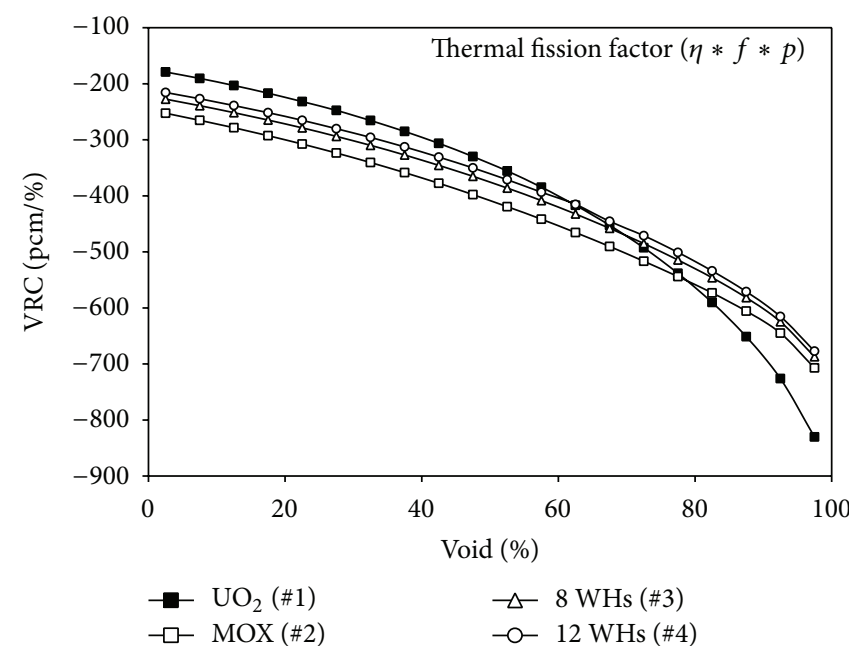

(a)

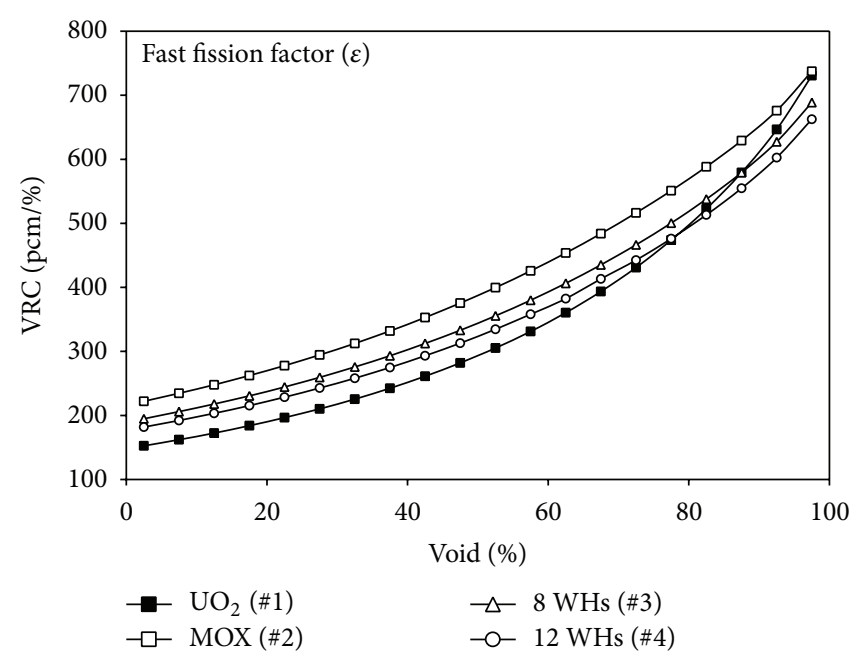

(b)

FIGURE 10: Values of void reactivity coefficients for thermal and fast fission factors.

with the enhanced moderation decreases by 6 and $20 \mathrm{pcm} / \%$ at $100 \%$ void fraction, respectively. Meanwhile, the values of the void reactivity coefficient for ${ }^{238} \mathrm{U}$ increase by $10 \mathrm{pcm} / \%$ at $100 \%$ void fraction.

\section{Conclusions}

The decomposition of the void reactivity coefficient by analyzing the influence of particular isotopes showed that fissile materials and ${ }^{157} \mathrm{Gd}$ contribute to the positive void effect in both uranium and MOX fuel assemblies. ${ }^{240} \mathrm{Pu}$ contributes to the positive effect at high void fraction as well. Negative void reactivity coefficient is mainly determined by ${ }^{238} \mathrm{U}$ isotope.

An important safety concern is a positive void reactivity coefficient at high void fraction for assembly design with fresh MOX fuel. Nevertheless, the study results indicated that positive values are observed only for the void fraction above $75 \%$, which is beyond normal operation conditions of BWR core. Positive values in this void fraction range may lead to decreased level of core controllability during transients such as a loss of coolant accident. The decomposition analysis showed that positive values for MOX fuel assembly design are determined by hard neutron spectrum. It was demonstrated that the negative reactivity effect due to the decrease of the thermal fission factor could be compensated and exceeded by the positive reactivity effect due to the increase of the fast fission factor in case of a very hard spectrum.

The analysis of innovative extra-moderated MOX assemblies indicated that values of void reactivity coefficient are decreasing with increase of the moderation-to-fuel ratio. In addition, the decomposition analysis provided valuable information on the contribution of enhanced moderation to the softening of neutron spectrum and its influence on the decrease of the void coefficient for particular isotopes.

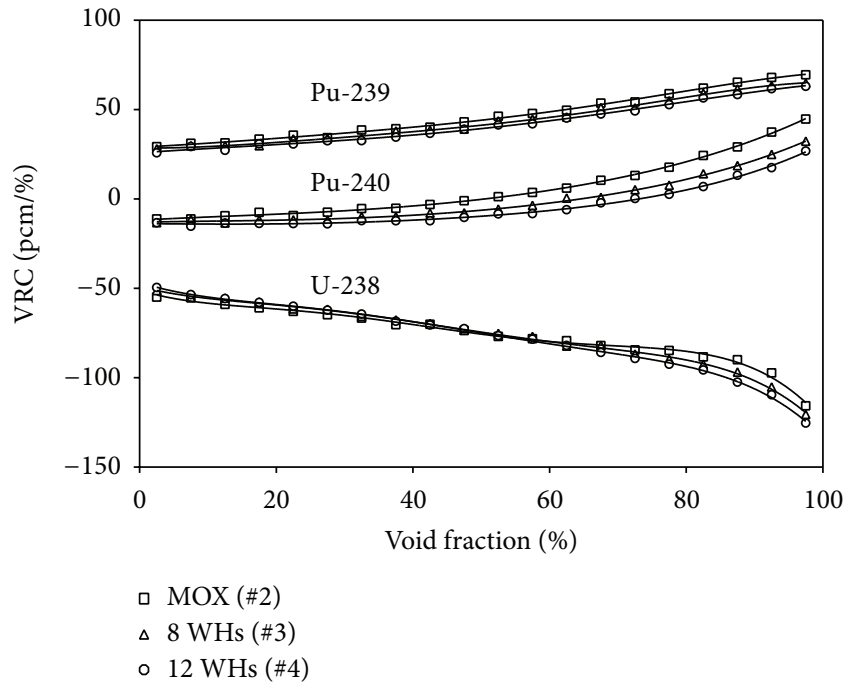

FIGURE 11: Values of void reactivity coefficients for separate isotopes in modified MOX fuel assemblies.

\section{Conflict of Interests}

The authors declare that there is no conflict of interests regarding the publication of this paper.

\section{References}

[1] A. Slavickas, R. Pabarčius, A. Tonkūnas, and G. Stankūnas, "Decomposition analysis of void reactivity coefficient for innovative and modified BWR assemblies," Science and Technology of Nuclear Installations, vol. 2014, Article ID 132737, 9 pages, 2014.

[2] P. Blaise, N. Huot, N. Thiollay, P. Fougeras, and A. Santamarina, "High-burn up $10 \times 10100 \%$ MOX ABWR core physics analysis 
with APOLLO2.8 and TRIPOLI-4.5 codes," Annals of Nuclear Energy, vol. 37, no. 7, pp. 899-909, 2010.

[3] K. I. Björk, V. Fhager, and C. Demazière, "Comparison of thorium-based fuels with different fissile components in existing boiling water reactors," Progress in Nuclear Energy, vol. 53, no. 6, pp. 618-625, 2011.

[4] A. A. Galahom, I. I. Bashter, and M. Aziz, "Study the neutronic analysis and burnup for BWR fueled with hydride fuel using MCNPX code," Progress in Nuclear Energy, vol. 77, pp. 65-71, 2014.

[5] Z. Jitka and J. Wallenius, "Void reactivity feedback in BWRs with MA bearing MOX fuels," Annals of Nuclear Energy, vol. 38, no. 9, pp. 1968-1977, 2011.

[6] A. Yamamoto, T. Ikehara, I. T. O. Takuya, and E. Saji, "Benchmark problem suite for reactor physics study of LWR next generation fuels," Journal of Nuclear Science and Technology, vol. 39, no. 8, pp. 900-912, 2002.

[7] M. D. DeHart, "Lattice physics capabilities of the SCALE code system using TRITON," in Proceedings of the International Conference on the Physics of Reactors, Vancouver, Canada, September 2006.

[8] H. R. Trellue, "Safety and neutronics: a comparison of MOX vs $\mathrm{UO}_{2}$ fuel," Progress in Nuclear Energy, vol. 48, no. 2, pp. 135-145, 2006.

[9] R. Ramirez-Sanchez, R. T. Perry, V. Gustavo Alonso, and H. Javier Palacios, "MOX fuel assembly design equivalent to enriched uranium fuel for BWR," in Proceedings of the International Conference on the Physics of Reactors "Nuclear Power: A Sustainable Resource", Casino-Kursaal Conference Center, Interlaken, Switzerland, September 2008.

[10] J. L. François, C. M. D. Campo, and J. Hernández, "Design of an overmoderated fuel and a full MOX core for plutonium consumption in boiling water reactors," Annals of Nuclear Energy, vol. 29, no. 16, pp. 1953-1965, 2002.

[11] T. Yamamoto, T. Umano, R. Kanda et al., "Core physics experiments and their analysis of high moderation full MOX BWR," in Proceedings of the International Conference on Global Environment and Advanced Nuclear Power Plants (GENES4/ANP '03), Kyoto, Japan, September 2003.

[12] F. Franceschini and B. Petrović, "Core physics analysis of $100 \%$ MOX core in IRIS," Annals of Nuclear Energy, vol. 35, no. 9, pp. 1587-1597, 2008.

[13] SCALE: A Comprehensive Modeling and Simulation Suite for Nuclear Safety Analysis and Design, ORNL/TM-2005/39, Version 6.1, Oak Ridge National Laboratory, Oak Ridge, Tenn, USA, Radiation Safety Information Computational Center, Oak Ridge National Laboratory as CCC-785, 2011.

[14] M. Pecchia, G. Kotev, C. Parisi, and F. D’Auria, "MOx benchmark calculations by deterministic and Monte Carlo codes," Nuclear Engineering and Design, vol. 246, pp. 63-68, 2012.

[15] J. L. Francois and C. M. del Campo, "Lattice physics codes comparisons for the NEA BWR-MOX benchmark," in Proceedings of the International Topical Meeting on Advances in Reactor Physics and Mathematics and Computation into the Next Millennium, Pittsburgh, Pa, USA, May 2000. 


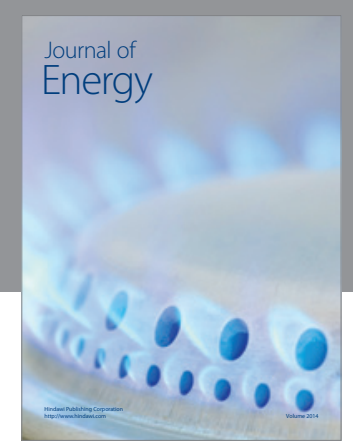

Journal of

Industrial Engineering
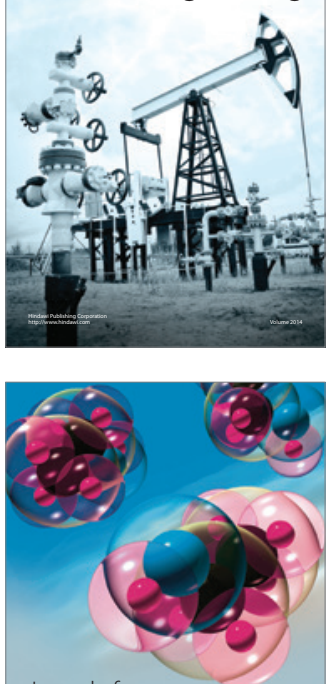

Fuels
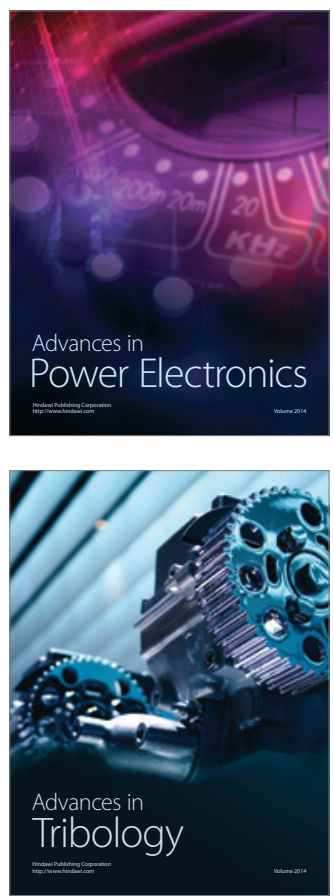

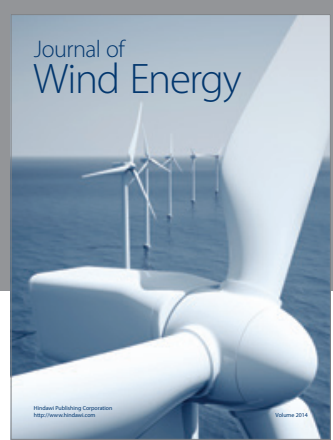

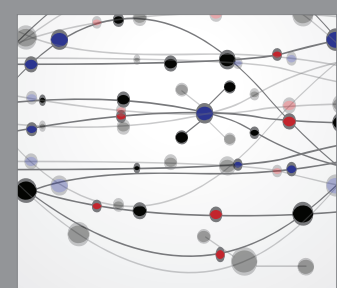

The Scientific World Journal

Submit your manuscripts at http://www.hindawi.com

Journal of

Structures
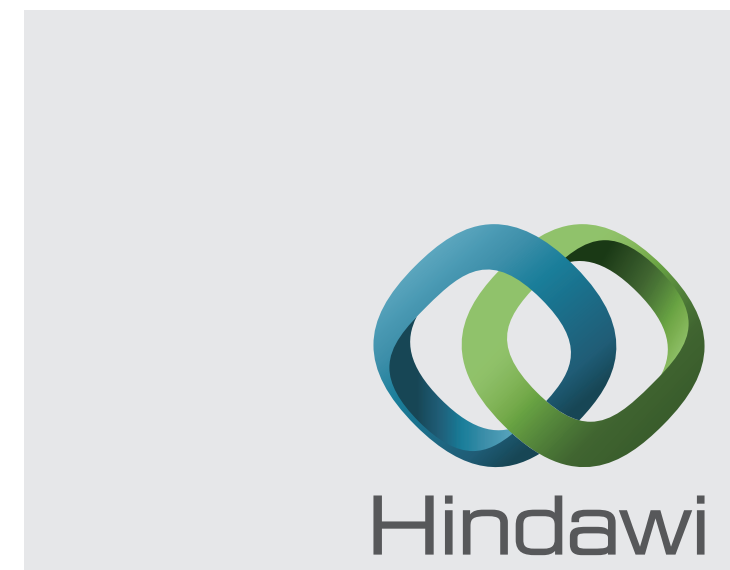

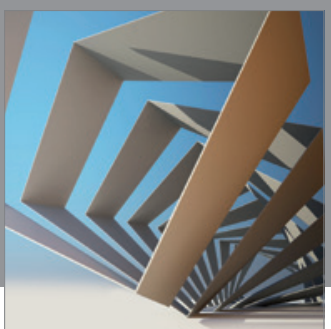

Rotating

Machinery
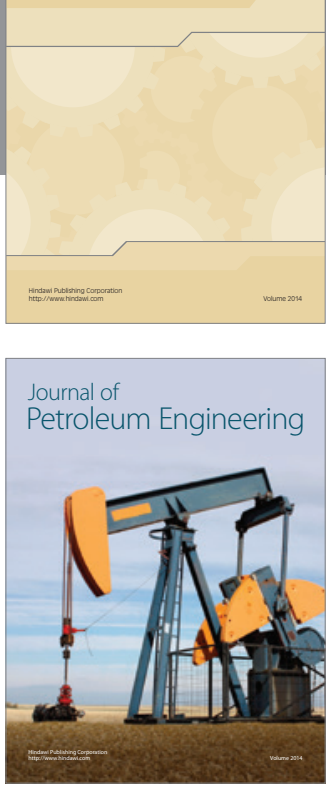

Journal of

Solar Energy
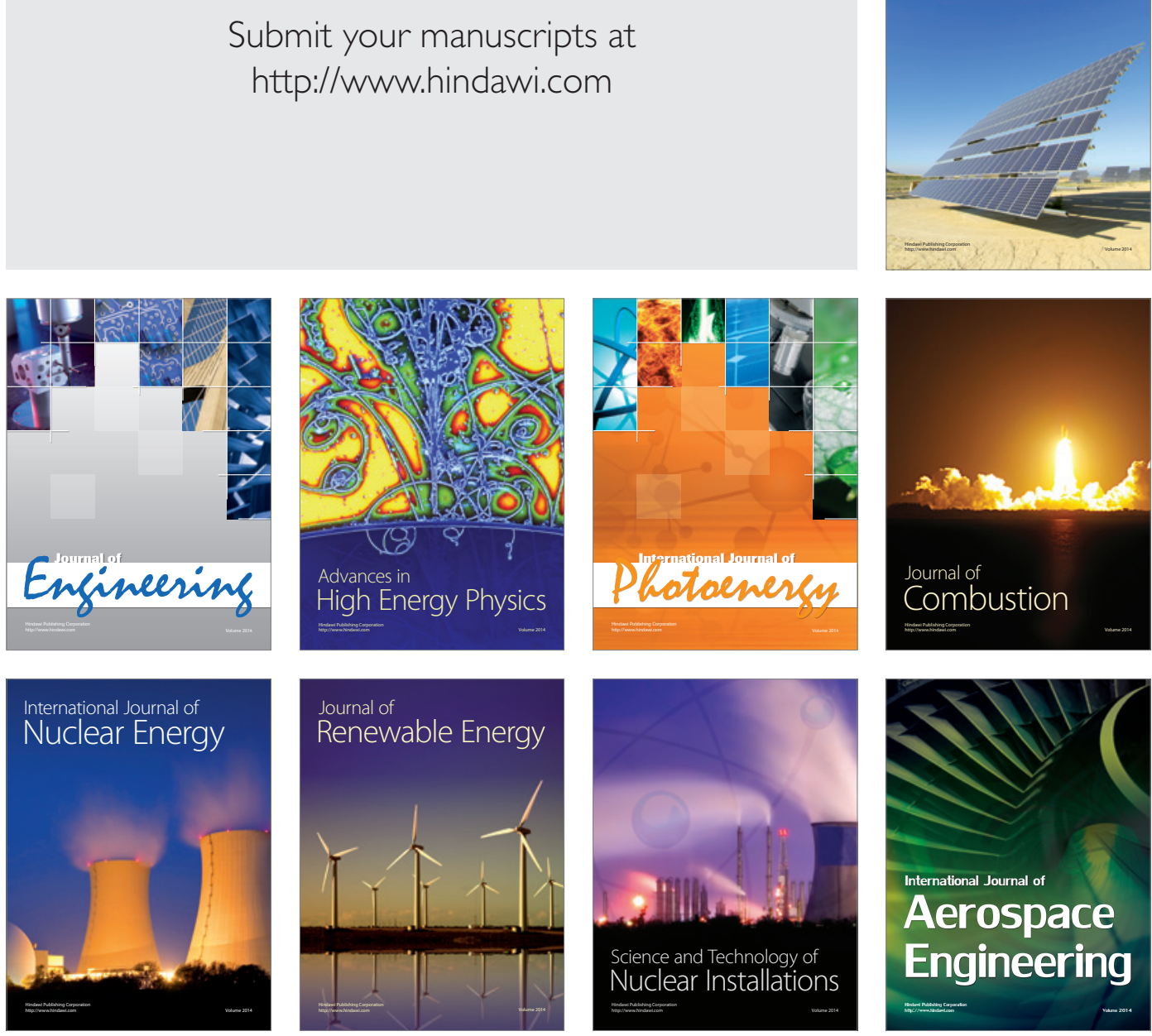